\title{
The Importance Of Technology Usage In The Classroom, Does Gender Gaps Exist
}

Marsha Mims-Word, Bowie State University, USA

\begin{abstract}
A decade ago, access to technology was limited and wiring schools was one of the nation's highest education priorities (NCREL, 2005). Ten years of substantial investments have vastly improved this picture. According to the Secretary's Fourth Annual Report on Teacher Quality, virtually every school with access to computers has Internet access (99\%), compared to only 35 percent of schools in 1994, according to the National Center for Education Statistics (NCES) (Parsad \& Jones, 2005).

The Office of Technology Assessment report to Congress in 1995 stated that "Technology is not central to the teacher preparation experience in most colleges of education. ...most new teachers graduate from teacher preparation institutions with limited knowledge of the ways technology can be used in their professional practice" (Office of Technology Assessment, 1995). The report, in which this statement appeared, titled Teachers and Technology: Making the Connection, was a wake-up call, and over the past years, much remunerative progress has been made.
\end{abstract}

Many states are attempting to address educators' technology skills through the creation of teacher or administrator standards that include technology; as of 2003, 40 states and the District of Columbia have such standards (Ansell \& Park, 2003). A number of states have adopted technology requirements for initial licensure. For example, 13 states require teachers and/or administrators to complete technology-related coursework, and nine require them to pass technology-related assessments. In addition, a number of states have implemented policies to improve veteran teachers' technological skills (Ansell \&Park, 2003).

Addressing the issues of technology integration into the curriculum, the Maryland State Department of Education's (MSDE) PT3 consortium infused technology into the state's teacher education programs in three ways. First, the consortium used the Maryland Teacher Technology Standards to redesign both arts and sciences and education courses so they incorporate technology-related knowledge and skills. The Maryland Teacher Technology Standards included learning outcomes and, core learning goals and skills for success; it also specifies what students in prekindergarten through $12^{\text {th }}$ grade need to know and be able to do in English/Language Arts, mathematics, science, and social studies. The Maryland State Department of Education (1999) provided expectations for how technology can and should be used to support student learning and instruction. Second, the group developed performance assessments in order to measure the technological competence of teacher candidates. Third, the consortium developed a system for electronic portfolios that incorporates a student teacher's technology performance assessment. These portfolios can be made available to future employers to demonstrate technology-related proficiency. The consortium is statewide and diverse, including several public universities and two communities.

According to a report titled, Tech-Savvy: Educating Girls in the New Computer Age (AAUW, 2000), Washington, $D C$; as violent electronic games and dull programming classes turn off increasing numbers of adolescent girls, the way information technology is used, applied, and taught in the nation's classrooms must change. Furthermore, commensurate with rapid changes in technology, a remarkably consistent picture emerges: more boys than girls experience an early, passionate attachment to computers, whereas for most girls attachment is subdued.

Margolis and Fisher (2002) reported that computing is claimed as "male territory" very early in life: from early childhood through college, computing is both actively claimed as "guy stuff" by boys and men and passively ceded by girls and women. Society and culture have linked interest and success with computers to boys and men. In the words of Margolis and Fisher (2002), "curriculum, teachers' expectations, and culture reflect boys' pathways into computing, accepting both assumptions of male excellence and women's deficiencies in the field" ( $p .4)$.

(C) 2012 The Clute Institute http://www.cluteinstitute.com/ 
Social expectations towards educational leadership in academic and economics terms depend on the integration of technology in every facet of society. The American family survival depends on the abilities and incomes of all adults. The type of technical skills needed to be creative and to survive in the job market escalates daily. Educational leaders must be aware that gender equity among middle school students with respect to the use of computer technology should be grounded in the development of programs that not only address the educational aspect of schools, but also allow students to develop their appreciation for, and understanding of the interrelationship among computer usage, careers, and values. With the implementation of such programs, schools could operate as equalizers for the sexes regarding computer competency and attitudes. Educational leaders have the ability to direct resources to show how computer technology may release the creative impulse in children and allow them to think and learn.

Educators need to link the curriculum and technology with student interests. Both male and female students use computer applications that can be linked to the educational setting, such as word processing, Internet, completing homework, reports, and projects, as well as communication through email, self-expression, and personal interest. Educators who are developing these programs must understand how girls lose interest in technology and recognize the different learning styles of each gender.

The role of training district school teachers to effectively utilize computer technology within the classroom is important if strides are to be made in supporting girls and women in choosing computer-related careers and using computers as a medium of expression. Institutions of higher education would provide opportunities and hold the responsibility of reviewing the technical construction of each teacher's plan. Educational leaders will meet frequently with university representatives to review, discuss, record experiences, develop, modify, and evaluate plans and performances to ensure that teachers receive the training necessary to instruct all students utilizing appropriate computer technology. Degree attainment, certification, and re-certification should be linked to the variation of experiences, the structure, depth, detail, and impact of the program developed by the practitioner in consultation with representatives from higher education and the school district. Partnerships with local school districts and institutions of higher learner should be established to develop programs, which incorporate many of the tenets discussed above.

Keywords: Technology Usage; Gender; Teacher Training; Curriculum and Technology; Technology Integration

\section{INTRODUCTION}

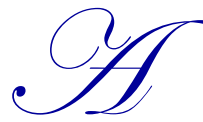

decade ago, access to technology was limited and wiring schools was one of the nation's highest education priorities (NCREL, 2005). Ten years of substantial investments have vastly improved this picture. According to the Secretary's Fourth Annual Report on Teacher Quality, virtually every school with access to computers has Internet access (99\%), compared to only 35 percent of schools in 1994, according to the National Center for Education Statistics (NCES) (Parsad \& Jones, 2005). According to NCREL (2005) in 1994, 3 percent of public school instructional rooms had Internet access, compared with 93 percent in 2003. And between 1998 and 2003, the student-to-connected-computer ratio went from 12-to-1 to 4.4-to-1 (NCREL, 2005). Many different types of technology can be used to support and enhance learning. Everything from video content and digital moviemaking to laptop computing and handheld technologies (Marshall, 2002) have been used in classrooms, and new uses of technology such as podcasting are constantly emerging (NCREL, 2005).

\section{GENDER DIFFERENCES}

According to a report titled, Tech-Savvy: Educating Girls in the New Computer Age (AAUW, 2000), Washington, $D C$; as violent electronic games and dull programming classes turn off increasing numbers of adolescent girls, the way information technology is used, applied, and taught in the nation's classrooms must change. Furthermore, commensurate with rapid changes in technology, a remarkably consistent picture emerges: more boys than girls experience an early, passionate attachment to computers, whereas for most girls attachment is subdued. Among others, Margolis and Fisher (2002) stated that adolescence is a period of heightened risk and although the age is difficult for everyone, one of its most dramatic impacts is a drop in girls' sense of confidence and 
competence. Such emotional and physical changes also introduce new interests, challenges, and stress, all of which conspire against girls' focusing on technical training. Among other consequences, gender under representation within the field holds high stakes for the national economy. The information technology profession is in the midst of a severe workforce shortage; according to Margolis and Fisher (2002), it is estimated that more than 900,000 public and private--sector jobs remain unfilled. The cost to the economy of this labor shortage has been estimated between $\$ 3$ billion and \$4 billion per year in Silicon Valley alone. Yet, every day, talented girls and women who could fill these gaps are disaffected or discouraged from pursuing computing careers (Margolis \& Fisher, 2002).

Margolis and Fisher (2002) reported that computing is claimed as "male territory" very early in life: from early childhood through college, computing is both actively claimed as "guy stuff" by boys and men and passively ceded by girls and women. Society and culture have linked interest and success with computers to boys and men. In the words of Margolis and Fisher (2002), "curriculum, teachers' expectations, and culture reflect boys' pathways into computing, accepting both assumptions of male excellence and women's deficiencies in the field" (p. 4).

Programs developed to increase girls' enthusiasm for computer usage have created inclusive teaching techniques and curricula that can reach all students (Thom, 2001). Although such instruction can mitigate the resounding effects of gender bias, gender gaps still exist. Thom (2001) stated that "Innovative teaching does not automatically make it into mainstream classroom, and girls in poor and rural areas and students of color may not experience enough of the benefits that model teaching techniques offer" (p. 31).

By 1999, it was found that girls were narrowing the gender gap in science and math but not in technology (Eck, Hale, Ruff \& Tjelmeland, 1999). This gap only increased as students progressed in their schooling, whereupon the ratio of girls to boys on computers was 1:4 (Title IX at 30: Report Card on Gender Equity, 2002). Women were not always absent from the computer culture. Females in earlier decades lived well inside the world of computer programming-- not just the world of computer use. One of the first programmers was Augusta Ada Lovelace, who wrote the instructions for Babbage's computing machine in the 1800's; Adele Goldstine wrote the first programs for the Electronic Numerical Integrator and Computer (ENIAC) in the 1940's; and Grace Hopper was central to the development of Common Business Oriented Language( COBOL). During the mid 1980's and earlier, gender differences existed in home computer use, types of courses participated in by girls and boys, and their gender responses to computer games (Lockheed 1985). The Eisenhower National Clearinghouse for Mathematics and Science Education, a federally funded organization, predicted that the crisis in girls' attitudes toward math and science would bode; presages harmful effects on tomorrow's world. Science and technology must no longer remain a white male preserve, and the absence of women from the decision-making levels of science has produced a science that views the world from a male perspective--one which is, therefore, womanless. Teasdale and Lupart (2001) reported that a major initiative to address the concerns of under-representation of girls in the computer science and technology fields was undertaken by the American Association of University Women's Educational Foundation Commission on Technology, Gender, and Teacher Education. An on-line survey of 900 teachers and qualitative focus groups with 70 female students was collected across the United States. The results of the American Association of University Women's Educational Foundation Commission revealed that women are at a disadvantage when it comes to computer skills and knowledge and females tended to have higher reservations about the computer culture. Their findings also revealed that females are used to restricting their computer tools and tend not to be computer fluent. Females are much more inclined to take computer tool courses that teach skills such as page layout, spreadsheet use, PowerPoint, or word processing than to undertake actual programming and software design courses. While using these tools may be useful, it is by no means the same as being truly technologically literate.

\section{TEACHER PREPARATION AND TECHNOLOGY}

The Office of Technology Assessment report to Congress in 1995 stated that "Technology is not central to the teacher preparation experience in most colleges of education. ...most new teachers graduate from teacher preparation institutions with limited knowledge of the ways technology can be used in their professional practice" (Office of Technology Assessment, 1995). The report, in which this statement appeared, titled Teachers and Technology: Making the Connection, was a wake-up call, and over the past years, much remunerative progress has been made. With the help of federal, state, foundation, and private-sector funding, teacher education institutions have invested hundreds of millions of dollars in computer hardware, software, Internet connections, faculty training, 
and technical support. An example of this investment was the federal government's Preparing Tomorrow's Teachers to Use Technology (PT3) Program allocating numerous grants to teacher education programs. During the Bush Administration, the development of the No Child Left Behind emphasized the improvement of student achievement in academics with the use of technology on the elementary and secondary levels (Learning Point Associates, 2006). The No Child Left Behind (NCLB) legislation further call attention to the importance of leveraging the power of technology in all areas of K-12 education, from reading to science to special education. As a result, education leaders at the state and local levels are expected to develop plans that effectively employ technology to enhance learning and increase student achievement (Education Development Center, 2002). Standards for new teachers require training in technology, and the National Council for Accreditation of Teacher Education (NCATE) requires substantial technology focus throughout all programs it accredits. The North Central regional Education Laboratory three pre-service programs preparing tomorrow's teachers in use of technology study indicated that new teachers are entering the schools well prepared in the two areas: first, confidence and readiness to use technology as a tool for instruction and finally, general preparedness for the culture of the urban or rural schools in which they are student teaching or working after graduation (NCREL, 2003).

Many states are attempting to address educators' technology skills through the creation of teacher or administrator standards that include technology; as of 2003, 40 states and the District of Columbia have such standards (Ansell \& Park, 2003). A number of states have adopted technology requirements for initial licensure. For example, 13 states require teachers and/or administrators to complete technology-related coursework, and nine require them to pass technology-related assessments. In addition, a number of states have implemented policies to improve veteran teachers' technological skills (Ansell \&Park, 2003).

Addressing the issues of technology integration into the curriculum, the Maryland State Department of Education's (MSDE) PT3 consortium infused technology into the state's teacher education programs in three ways. First, the consortium used the Maryland Teacher Technology Standards to redesign both arts and sciences and education courses so they incorporate technology-related knowledge and skills. The Maryland Teacher Technology Standards included learning outcomes and, core learning goals and skills for success; it also specifies what students in pre-kindergarten through $12^{\text {th }}$ grade need to know and be able to do in English/Language Arts, mathematics, science, and social studies. The Maryland State Department of Education (1999) provided expectations for how technology can and should be used to support student learning and instruction. Second, the group developed performance assessments in order to measure the technological competence of teacher candidates. Third, the consortium developed a system for electronic portfolios that incorporates a student teacher's technology performance assessment. These portfolios can be made available to future employers to demonstrate technologyrelated proficiency. The consortium is statewide and diverse, including several public universities and two communities.

\section{SOCIETY ROLE}

Social expectations towards educational leadership in academic and economics terms depend on the integration of technology in every facet of society. The American family survival depends on the abilities and incomes of all adults. The type of technical skills needed to be creative and to survive in the job market escalates daily. Educational leaders must be aware that gender equity among middle school students with respect to the use of computer technology should be grounded in the development of programs that not only address the educational aspect of schools, but also allow students to develop their appreciation for, and understanding of the interrelationship among computer usage, careers, and values. With the implementation of such programs, schools could operate as equalizers for the sexes regarding computer competency and attitudes. Educational leaders have the ability to direct resources to show how computer technology may release the creative impulse in children and allow them to think and learn. Research has indicated that there are many factors in and outside the classroom that have resulted in girls being turned away from computer technology. The implications of these factors include media depicting men as experts in technology, societal expectations of different goals for boys and girls, the structure of learning tasks, the nature of feedback in performance situations, and the organization of the classroom seating. Parents and teachers should be sensitive to cultural biases and strive to expose both sexes to the advantages of computer technology. 
Educators need to link the curriculum and technology with student interests. Both male and female students use computer applications that can be linked to the educational setting, such as word processing, Internet, completing homework, reports, and projects, as well as communication through email, self-expression, and personal interest. Educators who are developing these programs must understand how girls lose interest in technology and recognize the different learning styles of each gender.

The role of training district school teachers to effectively utilize computer technology within the classroom is important if strides are to be made in supporting girls and women in choosing computer-related careers and using computers as a medium of expression. Institutions of higher education would provide opportunities and hold the responsibility of reviewing the technical construction of each teacher's plan. Educational leaders will meet frequently with university representatives to review, discuss, record experiences, develop, modify, and evaluate plans and performances to ensure that teachers receive the training necessary to instruct all students utilizing appropriate computer technology. Degree attainment, certification, and re-certification should be linked to the variation of experiences, the structure, depth, detail, and impact of the program developed by the practitioner in consultation with representatives from higher education and the school district. Partnerships with local school districts and institutions of higher learner should be established to develop programs, which incorporate many of the tenets discussed above.

\section{FINDINGS}

The overall findings indicate that, on some level both groups of students were able to navigate computer technology; however, gender differences appeared in relation to specific computer activities. The fact that the number of male students indicated in higher numbers that they would work harder if computers were used more is an indication that discovering and exploring the computer is a classic norm for male students. Males start programming early; they develop a sense of familiarity; they tinker on the outside and inside at the hardware, and they develop a sense of mastery over the machine. They are often introduced to computer technology by a parent who is involved with it and who is able to spark an interest. Home use is normally the first introduction to computer gaming, which is another draw, designed to peak and engage boys' interest in the home environment. Both Sutton (1991) and Kay (1992) identified a trend in their meta-analyses of studies on gender differences in computer-related attitudes, namely that males tend to possess more positive attitudes than females. In the current study, computers in the homes, access to the Internet in the home environment, and the willingness to engage more often in school assignments at home if computers are used are a perfect examples of boys' positive attitudes towards computer technology.

The girls in the current study appeared to use computer technology just as much as the boys did at home, in contrast to what has been described in most previous studies (Kay, 1992; Sutton, 1991). Therefore, it may not be surprising that their attitudes were in many ways as positive as boys' attitudes. Girls are equal in reporting both home ownership and access to the Internet as boys, but as early as kindergarten, they are encouraged to use technology as a writing tool. By contrast, boys learn their way around, inside, and out the computer, which tends to build level of confidence and skill levels.

In today's society accessibility to computer technology at home is not uncommon. Stone's (1994) feminist concept describes gender as a social construction, which affects the way culture is experienced. Exposure to computers at home gives boys and girls equal footing with respect of the relationship to computer technology usage. However, it is common for parents to impart their computer enthusiasm and skills to their own children, and through early mastery acquired at home, children gain a competence and confidence they carry with them into school. Research confirms that home environments are an important factor in students' developing an interest in computer technology (Margolis \& Fisher, 2002).

\section{CONCLUSION}

In a time of advancing technologies, increasing global competition diverse demographic populations, and calls for reform within and around the school community, the educational leader will have to be better equipped than ever before. It is up to the educational leader to ensure the classroom teacher and students of today and tomorrow will have the requisite educational skills to be productive members of our vastly changing society. 


\section{AUTHOR INFORMATION}

Marsha Mims-Word joined the College of Education as the Assistant to the Dean for Outreach \& Doctoral Studies in 2005. Dr. Mims-Word has been employed with Bowie State University for a number of years in various positions, most recently as Director of Off-Campus Programs for the School of Graduate Students \& Continuing Education. Dr Mims-Word completed a Bachelor of Sciences in Business Administration, Master of Arts in Human Resource Development and a Doctor of Education in Educational Leadership from Bowie State University. Dedicating 30 years of service in the field of education, Dr. Mims-Word represents an individual that is committed to those whom she has touched throughout her career. E-mail: Mmword@bowiestate.edu

\section{REFERENCES}

1. American Association of University Women Educational Foundation (2000). Tech Savvy: Educating Girls in the New Computer Age. Washington, DC.

2. Ansell, S. \& Park, J. (2003). Tracking Tech Trends. Students computer use grows, but teacher need training. Education Week, 43-48.

3. Eck, J., Hale, M., Ruff, S., Tjelmeland, M. (1999). An Educator's Guide to Access Retrieved September 9, 2010, from http://lrs.ed.uiuc.edu/wp/access/index.html

4. Education Development Center (2002). Technology Briefs for No Child Left Behind Planners. Retrieved on September 7, 2010 from http://www.neirtec.org/products/techbriefs/index html.asp

5. Kay, Robin H. (1992). An analysis of methods used to examine gender differences in computer-related behaviors. Journal of Educational Computing Research, 8, 277-290.

6. Learning Point Associates (2006). Understanding the No Child Left Behind Act Technology Integration. Retrieved on September 9, 2010 from http://www.learningpt.org/pdfs/qkey3.pdf

7. Lockheed, M. (1985). Women, girls and computers: A first look at the evidence Sex Roles 13: 115-22. In Butler, D. (Ed.). Gender, Girls, and Computer Technology: What's the status now? (Clearing House, 73, (4), 225-29).

8. Margolis, J. \& Fisher, A. (2002). Unlocking the clubhouse: Women in computing. Cambridge, MASS: The MIT Press.

9. Marshall, J.M. (2002). Learning with technology: Evidence that technology can, and does, support learning. San Diego, CA: Cable in the Classroom. In NCREL (2005), Using technology to improve student achievement. Retrieved September 9, 2010, from

http://www.ncrel.org/sdrs/areas/issues/methods/technlgy/te800.htm

10. Maryland State Department of Education (1999). Preparing teachers for technology catalyst grant. Retrieved September 8, 2010, from, http://www.pt3.org/project_desc.php3?grantee_id=145.

11. North Central Regional Educational Laboratory (2003). Three pre-service programs preparing tomorrow's teachers in use of technology: A study in partnerships. Retrieved September 8, 2010, from, http://www.ncrel.org/tech/preservice/index.htm

12. North Central Regional Educational Laboratory (2005). Using technology to improve student achievement. Retrieved September 9, 2010, from, http://www.ncrel.org/sdrs/areas/issues/methods/technlgy/te800.htm

13. Office of Technology Assessment. (1995). Teachers and technology: Making the connection (OTA-HER616). Washington, DC: U.S. Government Printing Office. In NCREL (2003), Three preservice programs preparing tomorrow's teachers to use technology: A study in partnerships. Retrieved January 26, 2005, from, http://www.ncrel.org/tech/preservice/ref.htm

14. Parsad, B., and Jones, J.(2005). Internet access in U.S. public schools and classrooms: 1994-2003 (NCES 2005-015).U.S. Department of Education. Washington, DC: National Center for Education Statistics. In NCREL (2005), Using technology to improve student achievement. Retrieved September 9, 2010, from, http://www.ncrel.org/sdrs/areas/issues/methods/technlgy/te800.htm

15. Stone, L. (1994). The education feminist reader. New York: Routledge

16. Sutton, R. (1991). Equity and computers in the schools: A decade of research. Review of Educational Research, 61, 475-503.

17. Teasdale, S. \& Lupart, J. (2001). Gender differences in computer attitudes, skills, and perceived ability. Retrieved March 1, 2003, from, http://www.geomatics.ucalgary.ca/cwse/CompAtt.pgf. 
18. Thom, M. (2001). Balancing the equation: Where are women and girls in science, engineering and technology? New York: Prentice Hall.

19. Title IX at 30: Report Card on Gender Equity: A Report of the National Coalition for Women and Girls in Education. (June, 2002). Retrieved September 9, 2010, from, www.ncwge.org. 


\section{NOTES}

